\title{
Clinical features and cancer risk in families with pathogenic $C D H 1$ variants irrespective of clinical criteria
}

\author{
Rosa M Xicola, ${ }^{1}$ Shuwei Li (D) ,' ${ }^{2}$ Nicolette Rodriguez, ${ }^{1}$ Patrick Reinecke, ${ }^{2}$ \\ Rachid Karam, ${ }^{3}$ Virginia Speare, ${ }^{2}$ Mary Helen Black (D) , ${ }^{4}$ Holly LaDuca, ${ }^{2}$ \\ Xavier Llor (D) 1
}

\begin{abstract}
- Additional material is published online only. To view please visit the journal online (http://dx.doi.org/ 10.1136jmedgenet-2019105991).
\end{abstract}

Medicine, Yale University School of Medicine, New Haven, Connecticut, USA

${ }^{2}$ Clinical Diagnostics, Ambry Genetics Corporation, Aliso Viejo, California, USA

${ }^{3}$ Ambry Translational Genomics (ATG) Lab. Ambry Genetics Corporation, Aliso Viejo, California, USA

${ }^{4}$ Statistical Genetics, Ambry Genetics Corporation, Aliso Viejo, California, USA

\section{Correspondence to}

Dr Xavier Llor, Medicine, Yale University School of Medicine, New Haven, CT 06520-8019, USA; xavier.llor@yale.edu

RMX and SL are joint first authors.

Received 3 January 2019 Revised 5 June 2019 Accepted 13 June 2019 Published Online First 11 July 2019

\begin{abstract}
Background The clinical phenotype of $C D H 1$ pathogenic variant carriers has mostly been studied in families that fulfil criteria of hereditary diffuse gastric cancer (HDGC). We aimed at determining cancer phenotype and cancer risk estimation among families with $C D H 1$ pathogenic variants not selected by HDGC clinical criteria.

Methods Patients were all consecutively identified CDH1 pathogenic variant carriers from a clinical laboratory tested with multigene panel testing and from an academic cancer genetics programme. Clinical and demographic features, cancer phenotypes and genotype-phenotype correlations were determined among $\mathrm{CDH} 1$ families. Age-specific cumulative cancer risks (penetrance) were calculated based on 38 families with available pedigrees.
\end{abstract}

Results Within the $113 \mathrm{CDH} 1$ pathogenic variant probands and 476 relatives, 113 had gastric cancer, 177 breast cancer and 196 other cancers. Mean age at diagnosis was 47 for gastric and 54 for breast cancer. Forty-six per cent fulfilled criteria of HDGC. While $36 \%$ of families had both gastric and breast cancers, 36\% had breast but no gastric cancers and $16 \%$ had gastric but not breast cancers. Cumulative risk of cancer by age 80 was $37.2 \%$ for gastric and $42.9 \%$ for breast cancer. Conclusion In unselected $C D H 1$ pathogenic variant carrier families, gastric cancer risks were lower and age at diagnosis higher than previously reported in families pre-selected for HDGC criteria. A substantial proportion of families did not present with any gastric cancers and their cancers were limited to breast. Thus, clinical criteria for $\mathrm{CDH} 1$ testing should be widened, including breast cancer families only, and a consideration for delayed prophylactic gastrectomy/surveillance should be evaluated.

\section{INTRODUCTION}

Heterozygous germline variants in $\mathrm{CDH} 1$ have been involved as a cause of the hereditary diffuse gastric cancer syndrome (HDGC). ${ }^{1-3}$ The CDH1 gene encodes for E-cadherin, a cell-cell adhesion protein, vital to maintaining the integrity of cells and cohesion of tissues. Disruption of these junctions plays an important part in tumourigenesis. ${ }^{4}$ The lifetime risk of gastric cancer among CDH1 pathogenic variant carriers has been reported to be between 56\% and 83\% for women and 40\% and $70 \%$ for men. ${ }^{6}$ Additionally, the risk of lobular breast cancer (LBC) among female carriers has been reported to be between $39 \%$ and $42 \% .{ }^{56}$ Mean age at diagnosis has been reported at 40 (range, 14-85) for gastric cancers and 53 (range, 39-64) for breast cancers. $^{6}$ In view of these high cancer risks and early age of onset, prophylactic total gastrectomy is recommended for $\mathrm{CDH} 1$ pathogenic variant carriers between the ages of 18 and 40 years. ${ }^{78}$ For patients who choose not to undergo prophylactic gastrectomy, surveillance recommendations include endoscopy every 6-12 months with a minimum of 30 random biopsies with five taken from six established anatomical zones. ${ }^{79}$ Recent data suggest that following this careful approach, up to $60 \%$ of early lesions could be detected in asymptomatic carriers. ${ }^{10}$ However, early detection remains challenging given the multifocal and diffuse nature of this malignancy, which may not be visualised macroscopically. ${ }^{11}$ Conversely, surveillance recommendations for LBC endorse annual mammogram starting at age 30 years with consideration of both breast MRI with contrast and tomosynthesis. ${ }^{12}$ There is currently insufficient evidence for the role of mastectomy in $\mathrm{CDH} 1$ pathogenic variant carriers, ${ }^{12}$ but some experts suggest that prophylactic breast surgery can be offered in selected cases. ${ }^{13}$

An important limitation is that gastric and breast cancer risks have been described, for the most part, analysing a limited number of families highly enriched with gastric cancers, as they were pre-selected according to clinical criteria of HDGC. ${ }^{14}$ These criteria were recently broadened and they include (taking into account first-degree and second-degree relatives) (1) families with two or more patients with gastric cancer at any age, one confirmed DGC; (2) individuals with DGC before the age of 40; and (3) families with diagnoses of both DGC and LBC (one diagnosis before the age of 50). Additionally, CDH1 testing could be considered in patients with bilateral or familial LBC before the age of 50, patients with DGC and cleft lip/palate, and those with precursor lesions for signet ring cell carcinoma. ${ }^{8}$ Nevertheless, it is unclear if the same cancer risks apply to all CDH1 pathogenic variant carriers, regardless of cancer incidence in the family. This is becoming increasingly relevant since the generalisation of multigene

Rodriguez $\mathrm{N}$, et al.

2019:56:838-843. 
panel testing (MGPT), as more pathogenic CDH1 mutations are being identified outside cases strictly fulfilling diagnostic criteria for HDGC syndrome. ${ }^{15}$ In fact, a recent study found that up to $65 \%$ of $C D H 1$ pathogenic variant carriers do not meet HDGC diagnostic criteria for genetic testing. ${ }^{15}$ Altogether, this has prompted some experts to be cautious about recommending prophylactic gastrectomy for patients with a known pathogenic $\mathrm{CDH} 1$ variant but without a personal or family history of DGC or LBC.

This study aims to describe the phenotypic spectrum and assess gastric and breast cancer risks among a group of $\mathrm{CDH} 1$ pathogenic variant carriers, independent of the indication for hereditary cancer genetic testing, thus not previously selected by HDGC diagnostic criteria.

\section{METHODS}

\section{Patient ascertainment}

Probands and their first-degree and second-degree relatives included in this study were identified from Ambry Genetics and Yale's Smilow Cancer Genetics and Prevention Program. The project was deemed exempt from review for Ambry and was approved by Yale's Institutional Review Board. Ambry's proband cohort included all CDH1 pathogenic variant carriers $(n=105)$ identified through MGPT from March 2012 through December 2016 among 162472 patients referred for MGPT. Demographics, clinical characteristics and genes included in the MGPT are shown in online supplementary table 1 . The Yale cohort included all $(n=8)$ pathogenic variant carriers identified in the programme from June 2008 to July 2018, either through MGPT or CDH1 testing only who were not previously tested at Ambry Genetics. Only pathogenic or likely pathogenic variants were included. Pathogenic variants were identified per Ambry's classification schema, ${ }^{16}$ which is based on guidelines published by the American College of Medical Genetics and Genomics. ${ }^{17}$

\section{Clinical features and cancer prevalence among patients and their family members}

Only one $C D H 1$ carrier had a pathogenic variant in another cancer-predisposition gene (MSH6). Clinical phenotypes, including the prevalence of gastric and/or breast cancer, mean age at cancer diagnosis, sex, race and type of variant, were analysed for $C D H 1$ pathogenic variant carrier probands $(n=113)$ and family members for whom clinical history of cancer was available $(n=476)$. As cancer pathology reports of family members were not generally available, any affected family members with gastric cancer were assumed to have DGC for the purpose of calculating percentage of patients fulfilling HDGC clinical criteria. HDGC criteria pertaining to LBC was only considered for probands, as we could not be certain of the pathology for breast cancer of most family members and ductal breast cancer (DBC) is common in the general population. Finally, cancer prevalence was assessed considering first-degree and second-degree relatives.

\section{Cancer penetrance estimation}

Cancer penetrance was estimated analysing 38 families with pedigree information with at least all third-degree relatives and at least one individual affected with gastric cancer or breast cancer. Individuals with unknown $\mathrm{CDH} 1$ genotypes were considered 'missing' and there was no imputation in the penetrance calculation. A complete description of these families can be found in online supplementary table 2 . MENDEL software ${ }^{18}$ was used for the calculations. We parameterised the model in terms of log relative risk in variant carriers, assuming the cancer incidence is

\begin{tabular}{|c|c|c|c|c|}
\hline & $\begin{array}{l}\text { Probands } \\
\text { with } \\
\text { gastric } \\
\text { cancer } \\
\mathrm{n}=30^{*}\end{array}$ & $\begin{array}{l}\text { Probands } \\
\text { with } \\
\text { breast } \\
\text { cancer } \\
\mathrm{n}=54^{*}\end{array}$ & $\begin{array}{l}\text { Probands } \\
\text { with } \\
\text { other } \\
\text { cancers } \\
\mathrm{n}=7\end{array}$ & $\begin{array}{l}\text { Probands } \\
\text { with no } \\
\text { cancer } \\
\mathrm{n}=25\end{array}$ \\
\hline Average age at testing (SD) & $45(17)$ & $54(12)$ & $46(14)$ & $46(15)$ \\
\hline Female & 22 & 54 & 6 & 15 \\
\hline \multicolumn{5}{|l|}{ Ethnicity } \\
\hline Caucasian & 20 & 38 & 4 & 17 \\
\hline African American & 1 & 6 & 1 & 3 \\
\hline Hispanic & 7 & 2 & 1 & 2 \\
\hline Ashkenazi Jew & 2 & & 1 & 2 \\
\hline Asian & & 2 & & \\
\hline Other & & 1 & & \\
\hline Unknown & & 5 & & 1 \\
\hline Average age at diagnosis (SD) & $42(16)$ & $50(12)$ & $41(13)$ & \\
\hline \multicolumn{5}{|l|}{ Cancer type } \\
\hline Lobular breast cancer & & 26 & & \\
\hline Ductal breast cancer & & 18 & & \\
\hline Mixed (lobular and ductal) & & 3 & & \\
\hline $\begin{array}{l}\text { Diffuse/signet ring cell gastric } \\
\text { cancer }\end{array}$ & 19 & & & \\
\hline Adenocarcinoma & 2 & & & \\
\hline Not provided & 9 & 6 & & \\
\hline Colorectal & & & 4 & \\
\hline Ovary & & & 1 & \\
\hline Thyroid & & & 1 & \\
\hline Pancreas & & & 1 & \\
\hline
\end{tabular}

*The three cases with gastric and breast cancers are included in both categories.

the same for all families. Non-carriers of the CDH1 variants in each family were presumed to develop gastric or breast cancer according to the incidence rates of all races from SEER. ${ }^{19} 20$ The relative risk (RR) of gastric cancer was estimated for men and women separately in three age groups: 20-44, 45-59 and 60-85. RR for breast cancer was estimated only among women using the aforementioned approach. The $\mathrm{CDH} 1$ variant allele was presumed to be rare, with a frequency of $0.1 \%$ in the general population. We first computed cumulative incidence: $c u m$.inc $=$ $\sum_{k=1}^{n} i_{k} t_{k} \exp \left(\beta_{k}\right)$, where $i_{k}$ is the incidence rate in the $k$ th age band of length $t_{k}$ and $\beta_{k}$ is the log relative risk. Then, we calculated the age-specific cumulative risk: cum.risk $=1-\exp (-$ cum.inc). The corresponding CIs (95\% and 50\% CI) were computed using a parametric bootstrap with 10000 iterations. Specifically, 10 000 draws were taken from the normal distribution with parameter estimated by MENDEL. All other statistical analyses were conducted in R Statistical Computing V.3.2.3.

\section{RESULTS}

Clinical features of $\mathrm{CDH} 1$ pathogenic variant carrier probands None of the $113 \mathrm{CDH} 1$ carriers, except one, had a pathogenic variant in another known breast, ovarian or colon cancer predisposition gene. A single case also had an MSH6 pathogenic variant. This patient was diagnosed with DGC at age 16 . The patient's mother was a carrier of both variants and had not had any cancers by age 40 . Cancers in second-degree and thirddegree relatives included colorectal cancer (CRC), breast, endometrial, ovarian and thyroid.

Demographic and clinical features are summarised in table 1. CDH1 pathogenic variant carriers had an average age of 50 

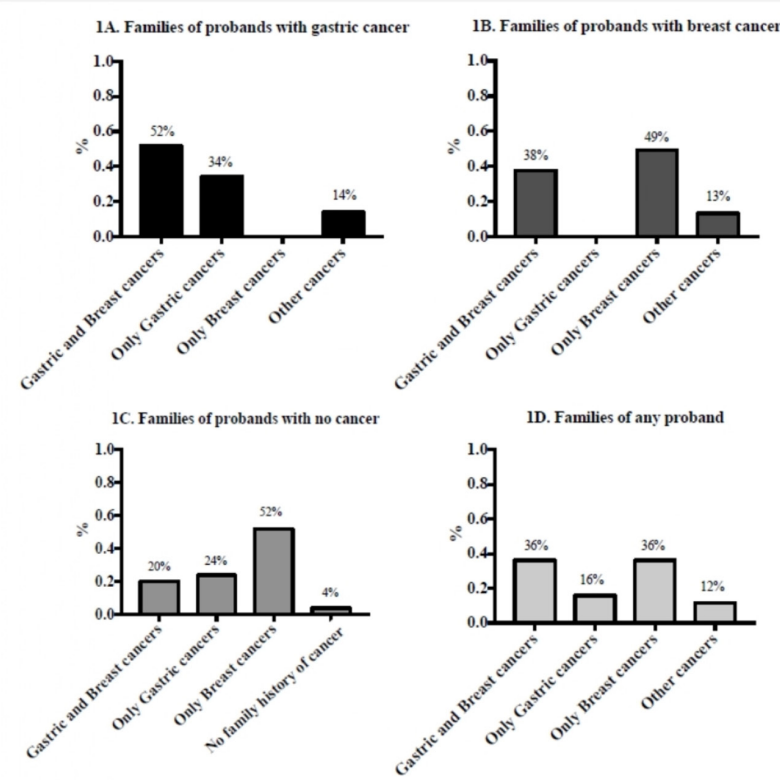

Figure 1 Cancer prevalence in families based on proband cancer history. (A) shows information on families from probands with gastric cancer. (B) shows that same information for probands with breast cancer. (C) shows cancers in families of patients with probands with no cancer. (D) shows the overall data from families of all probands included in the study. Two probands did not have information on cancer family history.

$( \pm 14)$ years at the time of genetic testing. Eighty-eight $(78 \%)$ had a personal history of cancer and 13 had a history of multiple cancer primaries. Three probands had both gastric and breast cancer. All variant carriers with breast cancer were women and had an average age at diagnosis of $50( \pm 12)$ years. Specific mean ages at diagnosis were $53( \pm 11)$ for LBC, $48( \pm 14)$ for DBC and $42( \pm 16)$ for gastric cancers, compared with 59, 63 and 68, respectively, for the general US population as reported through SEER data. ${ }^{21} 22$ Average age at diagnosis for colorectal, thyroid, pancreas and ovarian cancers were 50, 26, 48 and 56 years, respectively. Finally, the 25 probands with no personal history of cancer were on average $46( \pm 15)$ years old at the time of genetic testing, with ages ranging from 23 to 75 .

\section{Clinical features of the families of $\mathrm{CDH} 1$ pathogenic variant carrier probands}

There were a total of 476 individuals with cancer in the families included in this study: 113 gastric, 177 breast and 196 with other cancers. The mean diagnosis age was $47( \pm 14)$ years among family members with gastric cancer and $54( \pm 14)$ years among family members with breast cancer, therefore younger than reported in the general US population, 67.9 and 62.0 years, respectively,. ${ }^{21} 23$ From the 99 patients with complete information, up to $46 \%$ of families fulfilled HDGC criteria assuming all gastric cancers were of the diffuse type. Information on every single family and the different specific criteria they fulfil to qualify for HDGC is described in online supplementary table 3. While 29 families had incomplete information regarding breast tumour histology in family members, 18 fulfilled criteria 1 or 2, thus lack of breast tumour histology in family members was only a limitation in 11 families in order to determine HDGC fulfilment criteria. Fifty-three families (52\%) did not fulfil HDGC criteria. Only two families with probands with gastric cancer did not fulfil HDGC criteria. On the other hand, 33 families with probands with breast cancer did not fulfil the criteria. Thirty of those 33 did not have any family member with gastric cancer. Of the remaining three families, one family had an occurrence of gastric cancer at 48 and only the proband diagnosed with a ductal breast carcinoma; the second family had one member with gastric at 63 , several members with breast cancer diagnosed at older than 50 and the proband diagnosed at 43 with a ductal breast carcinoma; finally, the third family had a member with gastric cancer at 61 , one family member with breast cancer at 50 and the proband with lobular breast cancer at 54 . Sixteen of the 33 probands from families that did not fulfil criteria had a single lobular breast cancer and no gastric cancers.

\section{Cancer prevalence in families with $\mathrm{CDH} 1$ variant carrier probands}

Figure 1 shows the prevalence of the different types of cancers in the families of the pathogenic variant carriers based on reported proband cancer history (figure $1 \mathrm{~A}-\mathrm{C}$ ). Three phenotypic groups emerged from the analysis of the families with available family history: (1) mixed gastric/breast cancer (36\% of families); (2) breast cancer in the absence of gastric cancer $(36 \%$ of families); (3) gastric cancer in the absence of breast cancer $(16 \%$ of families). In the remaining $12 \%$ of families, no gastric or breast cancers were present.

\section{Cancer penetrance in families with $\mathrm{CDH} 1$ variant carrier probands}

Data on the 38 families used for pedigree-based penetrance analysis are summarised in online supplementary table 2. Specific fulfilment of HDGC criteria of all families is summarised in online supplementary table 3 . In the 20 pedigrees with at least one individual affected with gastric cancer, there were a total of 43 individuals with gastric cancer, 41 with breast cancer, and 678 with either another cancer type or with no cancer history. Likewise, 15 individuals with gastric cancer and five individuals with breast cancer carried a $C D H 1$ pathogenic variant; the remaining individuals with cancer (28 with gastric and 36 with breast) were not tested. On the other hand, 30 individuals with neither gastric nor breast cancer tested negative for CDH1.

In the 32 pedigrees with at least one patient with breast cancer, there were 84 individuals with breast cancer, 29 with gastric cancer, and 1105 with either another cancer type or with no cancer history. In these 32 families, 11 individuals with gastric and 19 individuals with breast cancer carried a CDH1 pathogenic variant; the other 18 gastric cancers and 64 breast cancers were not tested, and one patient with breast cancer tested negative. Separate LBC penetrance was not calculated as specific pathology reports were not available in many relatives of probands.

Cancer risk estimates are shown in table 2. The overall cumulative risk of gastric cancer by age 80 among the 20 families with at least one gastric cancer was $37.2 \%$ among men and $24.7 \%$ among women (table 2B). Cumulative risks of gastric cancer were relatively low until 40 years old at $2.8 \%$ and $1.3 \%$ for women and men, respectively, but nearly doubled each successive decade. The cumulative risk of breast cancer in women by age 80 among the 31 families with at least one breast cancer was 42.9\% (table 2B). Risk remained relatively low until 30-39 years old but increased significantly each decade thereafter (figure 2).

\section{CDH1 germline variants}

All specific $C D H 1$ likely pathogenic/pathogenic variants are listed in online supplementary table 4, along with their corresponding protein change and clinical history. Overall, 9.5\% of 
Table 2 Cancer risk estimates for gastric and breast cancer in $C D H 1$ probands

\begin{tabular}{|c|c|c|c|c|c|c|}
\hline \multicolumn{7}{|c|}{ (A) Penetrance model parameter estimates } \\
\hline & \multicolumn{3}{|l|}{ Male } & \multicolumn{3}{|l|}{ Female } \\
\hline $\begin{array}{l}\text { Age } \\
\text { group }\end{array}$ & $\log (R R)$ & SE & RR & $\log (\mathrm{RR})$ & SE & RR \\
\hline \multicolumn{7}{|c|}{ Gastric cancer } \\
\hline 20-44 & 3.65 & 0.94 & 38.47 & 4.40 & 0.93 & 81.77 \\
\hline $45-59$ & 3.49 & 0.98 & 32.85 & 3.49 & 0.98 & 32.90 \\
\hline $60-85$ & 3.44 & 1.04 & 31.28 & 3.45 & 1.05 & 31.37 \\
\hline \multicolumn{7}{|c|}{ Breast cancer } \\
\hline $20-85$ & - & - & - & 1.50 & 0.20 & 4.48 \\
\hline $20-49$ & - & - & - & 1.84 & 0.17 & 6.32 \\
\hline $50+$ & - & - & - & 1.33 & 0.21 & 3.79 \\
\hline \multicolumn{7}{|c|}{ (B) Cumulative risk } \\
\hline $\begin{array}{l}\text { Age } \\
\text { group }\end{array}$ & \multicolumn{3}{|l|}{ Male (\%) } & \multicolumn{3}{|c|}{ Female (\%) } \\
\hline $\begin{array}{l}\text { Gastric } \\
\text { cancer }\end{array}$ & Risk (\%) & \multicolumn{2}{|c|}{$95 \% \mathrm{Cl}(\%)$} & Risk (\%) & \multicolumn{2}{|c|}{$95 \% \mathrm{Cl}(\%)$} \\
\hline $20-29$ & 0.3 & 0.0 & 1.2 & 0.7 & 0.1 & 2.6 \\
\hline $30-39$ & 1.3 & 0.1 & 5.3 & 2.8 & 0.3 & 10.8 \\
\hline $40-49$ & 4.1 & 0.8 & 13.1 & 5.5 & 1.0 & 17.5 \\
\hline $50-59$ & 10.6 & 2.4 & 31.7 & 8.9 & 2.1 & 25.4 \\
\hline $60-69$ & 22.7 & 5.5 & 61.9 & 15.3 & 4.1 & 41.6 \\
\hline $70-79$ & 37.2 & 8.7 & 89.5 & 24.7 & 6.1 & 68.9 \\
\hline $\begin{array}{l}\text { Breast } \\
\text { cancer } \\
\text { female }\end{array}$ & Risk (\%) & \multicolumn{5}{|c|}{$95 \%$ Cl (\%) } \\
\hline $20-29$ & 0.5 & 0.4 & 0.7 & & & \\
\hline $30-39$ & 3.9 & 2.8 & 5.3 & & & \\
\hline $40-49$ & 13.0 & 9.7 & 17.3 & & & \\
\hline $50-59$ & 21.2 & 16.6 & 26.6 & & & \\
\hline $60-69$ & 32.2 & 25.1 & 40.7 & & & \\
\hline $70-79$ & 42.9 & 33.4 & 53.9 & & & \\
\hline
\end{tabular}

$R R$, relative risk.

variants in the present study were missense and $90.5 \%$ were pathogenic loss-of-function variants, similar to a previous study by Hansford et al. ${ }^{5}$ With the observed differentiated groups of cancer phenotype, we investigated any potential genotypephenotype correlation. No significant differences were observed in the distribution of types of genetic mutations among probands (table 3). Thus, $100 \%(n=30)$ of the mutations from probands with gastric cancer were loss-of-function mutations while for probands with breast cancer, $7 \%(\mathrm{n}=4)$ had missense mutations and $93 \%$ had loss-of-function mutations $(\mathrm{n}=50)$ (Fisher's exact test $\mathrm{p}=0.3$ ). As there was a significantly higher frequency of missense variants among probands without cancer in comparison with probands with gastric cancer $(p=0.006)$, we examined the family phenotypes of the former. Among these six families, two had gastric and breast cancers, three breast cancer only and one gastric cancer only. Two families fulfilled HDGC criteria. Thus, we did not observe a distinct cancer phenotype among families with missense variants and probands without cancer.

We also investigated whether a specific recurrent hotspot pathogenic variant was associated with a particular cancer phenotype. The most frequent mutation, p.C688*, was identified in nine Caucasian carriers. This variant is reported in ClinVar (https:// www.ncbi.nlm.nih.gov/clinvar/) by seven different clinical laboratories, but it is not present in the general population (gnomAD, http://gnomad.broadinstitute.org). Seven patients with this variant had breast cancer $(\mathrm{LBC}=5, \mathrm{DBC}=1$, other $=1)$, and two

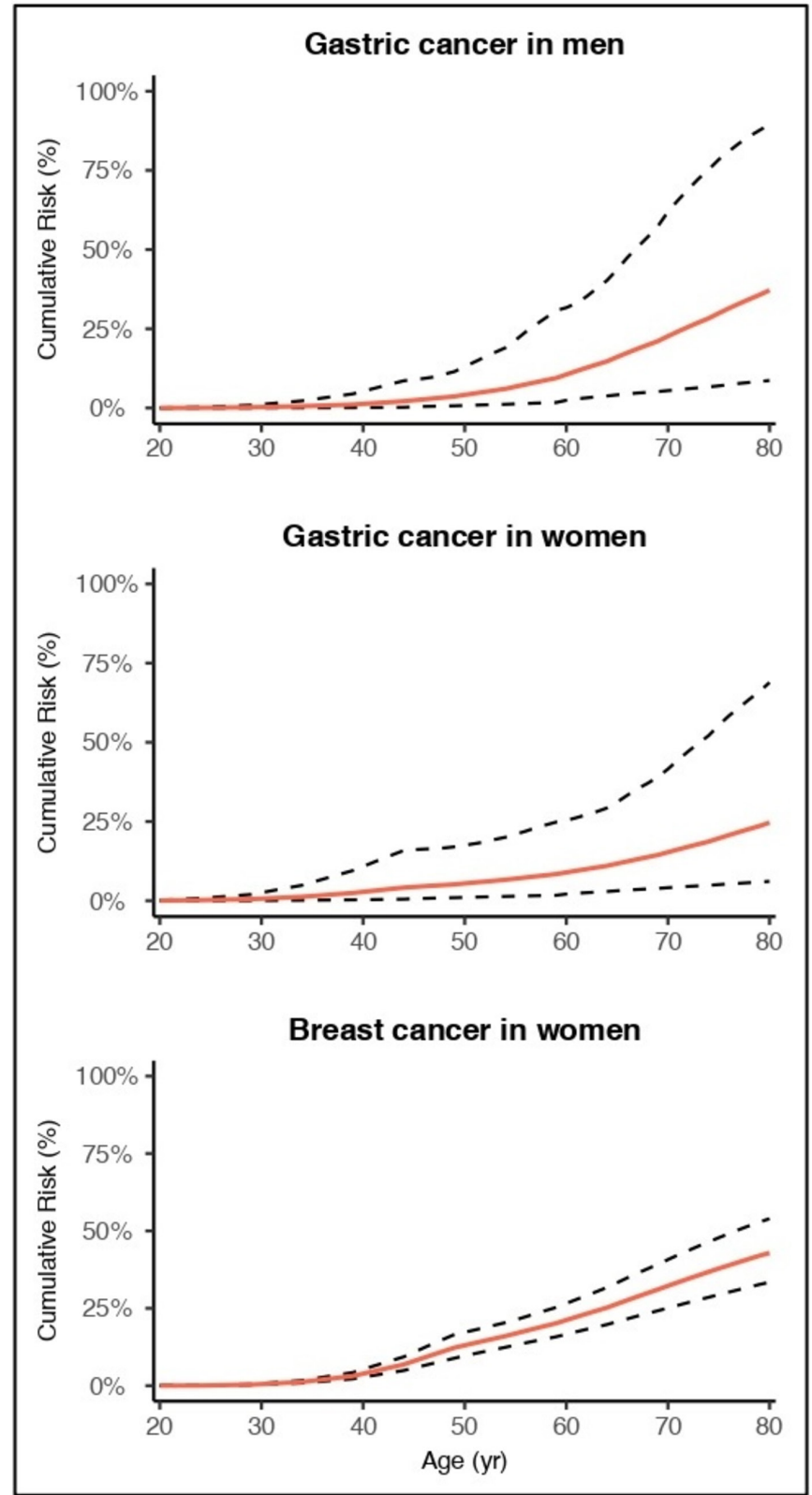

Figure 2 Cumulative risk curves for gastric and breast cancer in $\mathrm{CDH} 1$ probands. Top two graphs cumulative risk by age for gastric cancer (men and women) and bottom graph breast cancer (women only).

had gastric cancer $(\mathrm{DGC}=1$, no pathology available $=1)$. The second most frequent variant (p.D662*) was identified exclusively in African-American (AA) probands, accounting for 54.5\% $(n=6 / 11)$ of the CDH1 mutations observed in AA probands in our series. Currently, this variant is reported in ClinVar only by Ambry Genetics and it is not present in gnomAD. None of these six patients were referred from the same institution, and based

Table 3 Type of variants in $\mathrm{CDH} 1$ mutation probands

\begin{tabular}{llllll} 
Table 3 & Type of variants in CDH1 mutation probands & \\
\hline & $\begin{array}{l}\text { Gastric cancer } \\
\text { Type of mutation }\end{array}$ & $\begin{array}{l}\text { Breast cancer } \\
(\mathbf{n})\end{array}$ & $\begin{array}{l}\text { Other cancer } \\
(\mathbf{n})\end{array}$ & $\begin{array}{l}\text { No } \\
\text { cancer } \\
(\mathbf{n})\end{array}$ \\
\hline Missense & $0 \%$ & $7 \%(4)$ & $14 \%(1)$ & $24 \%(6)$ \\
Loss of function & $100 \%(30)$ & $93 \%(50)$ & $86 \%(6)$ & $76 \%(19)$ \\
\hline Loss of function included nonsense, frameshift, splicing variants ( $\pm 1.2 \mathrm{nt})$ and gross
\end{tabular}
del/dups. p.T379T, 2195G>A and p.G571S were classified as affecting splicing 2526 
on the demographic, clinical and pedigree information collected, it is unlikely they are closely related. Five of these six families only had breast cancers. One AA CDH1 carrier with this variant had no history of cancer. However, she was 40 years old at the time of data collection and under the average age of diagnosis for both gastric and breast cancer.

\section{DISCUSSION}

The body of literature on the clinical phenotype of CDH1 pathogenic variant carriers is still quite limited, which makes management particularly challenging. Furthermore, most studies defining this phenotype pre-selected variant carriers from families fulfilling clinical criteria for HDGC that tends to encompass the more visible cases. Remarkably, a recent study has shown that only $19 \%$ of families fulfilling these clinical criteria had CDH1 pathogenic variants, which suggests that either other genetic defects or shared environmental factors are behind most of these cases. ${ }^{5}$ On the other hand, while one study with a small number of carriers could not identify any $\mathrm{CDH} 1$ variants outside families that fulfil HDGC clinical criteria, ${ }^{24}$ the percentage of pathogenic variant carriers who do not fulfil these criteria and their clinical phenotype is still largely undefined.

Our study attempted to better understand the cancer phenotype of $\mathrm{CDH} 1$ pathogenic variant carriers without the bias of pre-selecting for HDGC clinical criteria. While an ideal study would involve a population-based cohort, this would be costprohibitive based on the sample size needed to ascertain an informative number of $\mathrm{CDH} 1$ carriers. Instead, we describe a cohort of $\mathrm{CDH} 1$ variant carriers identified through MGPT for inherited cancer susceptibility. While this sample is inherently enriched for patients with a personal and family history of cancer, probands were not selected based on meeting clinical criteria for HDGC. In fact, only $46 \%$ of $C D H 1$ carriers in this study met these criteria. While the full pedigrees were only available in a subset of cases, to our knowledge, this is the largest pedigree-based penetrance analysis in families not pre-selected for clinical criteria of HDGC.

From this cohort, we were able to draw several important conclusions. Thus, a similar proportion of families exhibited either the classical mixed gastric/breast cancer phenotype or a breast cancer phenotype in the absence of gastric cancer $(36 \%$ for each group). While the frequent occurrence of a breast cancer-only phenotype is likely reflective of referral for MGPT, the absence of gastric cancer in these families calls into question the pre-selection for testing based on HDGC criteria.

Lacking specific pathology data in many family members with breast cancer, we were not able to accurately measure penetrance for LBC. Taking all breast cancers together though, the risk of breast cancer by age 80 exceeded $40 \%$ in CDH1 carriers. Thus, it is sensible to include $\mathrm{CDH} 1$ in the genetic testing panels for families suspicious for an inherited breast cancer predisposition, even in the absence of gastric cancer.

Another important conclusion is that gastric cancer penetrance was much lower than previous reports, which is not entirely surprising considering that previous studies had pre-enriched cases based on clinical criteria. In fact, cancer risk by age 80 years was about half of what was previously reported: $37.2 \%$ for men and $24.4 \%$ for women in this cohort compared with $70.0 \%$ and $56.0 \%$, respectively, as reported by Hansford et al. ${ }^{5}$ Furthermore, the mean age at diagnosis of gastric cancers was 47 years, much higher than previously reported, ${ }^{6}$ and the cumulative risk remained relatively low until age 40 where it roughly doubled every decade thereafter. While we cannot make any direct implications in management from these data, a slightly more conservative approach regarding gastrectomies may be considered, particularly if a specific family has not presented with early gastric cancer cases. Nevertheless, caution should still be advised given the at most questionable efficacy of DGC screening.

Interestingly, on average all patients with cancer in these families, including DBC and CRC, were much younger than expected. It is unclear if this is a true result of carrying the pathogenic variants identified or if this is due to selection bias as these patients were more likely be tested for a genetic cancer predisposition.

Other limitations stem from the fact that, as mentioned above, this study is not population based and different clinical suspicion criteria for various inherited cancer syndromes were applied in order to proceed with genetic testing. Furthermore, complete pedigrees and pathology data were only available from a subset of families. Thus, while for the purpose of establishing fulfilment of HDGC clinical criteria we assumed that all gastric cancers in relatives of $\mathrm{CDH} 1$ variant carriers were of the diffuse type, we cannot totally be certain of that fact. Nevertheless, as the incidence of gastric cancer in the US population is quite low (lifetime risk of $0.8 \%$ ), and there is a well-established association between diffuse gastric cancer and $\mathrm{CDH} 1$ pathogenic variants, it is highly likely that, if not all, the great majority of the cases would be of this type.

Finally, we could not accurately estimate the frequency of de novo CDH1 variant cases, and thus data such as cancer penetrance should be interpreted in this context. Indeed, if there was a significant percentage of individuals with de novo variants, penetrance would likely be underestimated in this study.

In summary, we provide a broader view on the clinical phenotype of $C D H 1$ pathogenic variant carriers with lower penetrance for gastric cancer and a sizeable group of families that present with breast cancer only. Furthermore, a lower gastric cancer risk is observed as patients were not pre-selected for HDGC criteria. It is possible that other genetic or environmental factors may play a role in the penetrance and cancer risk. Better understanding of these factors will improve personalised risk assessment and clinical decision-making for $C D H 1$ variant carriers.

Contributors RMX, HL and XL designed and supervised the overall project. RMX, $N R, S L, R K, V S$ and PR compiled and analysed the data and performed the statistical analysis. RMX and XL interpreted the data and drafted the manuscript. They take full responsibility for the integrity of the data and the accuracy of the data analysis. MHB NR and SL critically revised the manuscript for important intellectual content.

Funding This work was supported by internal funds from the Yale Cancer Center (XL). RMX was supported by the Prevent Cancer Foundation.

Disclaimer The study sponsors had no role in the design of the study; in the collection, analysis or interpretation of the data; in the writing of the manuscript and in the decision to submit the manuscript for publication.

Competing interests SL, PR, RK, VS, MHB and HL work at Ambry Genetics. There are no competing interests for any author.

Patient consent for publication Not required.

Provenance and peer review Not commissioned; externally peer reviewed.

Data availability statement All data relevant to the study are included in the article or uploaded as online supplementary information.

\section{ORCID iDs}

Shuwei Li http://orcid.org/0000-0001-7176-1964

Mary Helen Black http://orcid.org/0000-0002-1654-0234

Xavier Llor http://orcid.org/0000-0002-6259-185X

\section{REFERENCES}

1 Guilford P, Hopkins J, Harraway J, McLeod M, McLeod N, Harawira P, Taite H, Scoular R, Miller A, Reeve AE. E-cadherin germline mutations in familial gastric cancer. Nature 1998:392:402-5 
2 Oliveira C, Senz J, Kaurah P, Pinheiro H, Sanges R, Haegert A, Corso G, Schouten J, Fitzgerald R, Vogelsang H, Keller G, Dwerryhouse S, Grimmer D, Chin S-F, Yang H-K, Jackson CE, Seruca R, Roviello F, Stupka E, Caldas C, Huntsman D. Germline $\mathrm{CDH} 1$ deletions in hereditary diffuse gastric cancer families. Hum Mol Genet 2009;18:1545-55.

3 Caldas C, Carneiro F, Lynch HT, Yokota J, Wiesner GL, Powell SM, Lewis FR, Huntsman DG, Pharoah PD, Jankowski JA, MacLeod P, Vogelsang H, Keller G, Park KG, Richards FM, Maher ER, Gayther SA, Oliveira C, Grehan N, Wight D, Seruca R, Roviello F, Ponder $B A$, Jackson CE. Familial gastric cancer: overview and guidelines for management. J Med Genet 1999;36:873-80.

4 Gall TMH, Frampton AE. Gene of the month: E-cadherin (CDH1). J Clin Pathol 2013;66:928-32.

5 Hansford S, Kaurah P, Li-Chang H, Woo M, Senz J, Pinheiro H, Schrader KA, Schaeffer DF, Shumansky K, Zogopoulos G, Santos TA, Claro I, Carvalho J, Nielsen C, Padilla S, Lum A, Talhouk A, Baker-Lange K, Richardson S, Lewis I, Lindor NM, Pennell E, MacMillan A, Fernandez B, Keller G, Lynch H, Shah SP, Guilford P, Gallinger S, Corso G, Roviello F, Caldas C, Oliveira C, Pharoah PDP, Huntsman DG. Hereditary diffuse gastric cancer syndrome: Cdh1 mutations and beyond. JAMA Oncol 2015;1:23-32.

6 Pharoah PD, Guilford P, Caldas C, International Gastric Cancer Linkage Consortium. Incidence of gastric cancer and breast cancer in $\mathrm{CDH} 1$ (E-cadherin) mutation carriers from hereditary diffuse gastric cancer families. Gastroenterology 2001;121:1348-53.

7 Network NCC. NCCN Clinical Practice Guidelines in Oncology-Gastric Cancer, 2017. Available: https://www.nccn.org/

8 van der Post RS, Vogelaar IP, Carneiro F, Guilford P, Huntsman D, Hoogerbrugge N, Caldas C, Schreiber KEC, Hardwick RH, Ausems MGEM, Bardram L, Benusiglio PR, Bisseling TM, Blair V, Bleiker E, Boussioutas A, Cats A, Coit D, DeGregorio L, Figueiredo J, Ford JM, Heijkoop E, Hermens R, Humar B, Kaurah P, Keller G, Lai J, Ligtenberg MJL, O'Donovan M, Oliveira C, Pinheiro H, Ragunath K, Rasenberg E, Richardson S, Roviello F, Schackert H, Seruca R, Taylor A, Ter Huurne A, Tischkowitz M, Joe STA, van Dijck $B$, van Grieken NCT, van Hillegersberg R, van Sandick JW, Vehof R, van Krieken JH, Fitzgerald RC. Hereditary diffuse gastric cancer: updated clinical guidelines with an emphasis on germline CDH1 mutation carriers. J Med Genet 2015;52:361-74

9 van der Post RS, Vogelaar IP, Manders P, van der Kolk LE, Cats A, van Hest LP, Sijmons R, Aalfs CM, Ausems MGEM, Gómez García EB, Wagner A, Hes FJ, Arts N, Mensenkamp AR, van Krieken JH, Hoogerbrugge N, Ligtenberg MJL. Accuracy of hereditary diffuse gastric cancer testing criteria and outcomes in patients with a germline mutation in CDH1. Gastroenterology 2015;149:897-906.

10 Mi EZ, Mi EZ, di Pietro M, O’Donovan M, Hardwick RH, Richardson S, Ziauddeen H, Fletcher PC, Caldas C, Tischkowitz M, Ragunath K, Fitzgerald RC. Comparative study of endoscopic surveillance in hereditary diffuse gastric cancer according to CDH1 mutation status. Gastrointest Endosc 2018;87:408-18.

11 Hebbard PC, Macmillan A, Huntsman D, Kaurah P, Carneiro F, Wen X, Kwan A, Boone D, Bursey F, Green J, Fernandez B, Fontaine D, Wirtzfeld DA. Prophylactic total gastrectomy (PTG) for hereditary diffuse gastric cancer (HDGC): the Newfoundland experience with 23 patients. Ann Surg Oncol 2009;16:1890-5.

12 Network NCC. NCCN Clinical Practice Guidelines in Oncology-Genetic/Familial HighRisk Assessment: Breast and Ovarian, 2017. Available: https://www.nccn.org/

13 Corso G, Figueiredo J, La Vecchia C, Veronesi P, Pravettoni G, Macis D, Karam R, Lo Gullo R, Provenzano E, Toesca A, Mazzocco K, Carneiro F, Seruca R, Melo S, Schmitt F, Roviello F, De Scalzi AM, Intra M, Feroce I, De Camilli E, Villardita MG, Trentin C, De Lorenzi F, Bonanni B, Galimberti V. Hereditary lobular breast cancer with an emphasis on E-cadherin genetic defect. J Med Genet 2018;55:431-41.
14 Fitzgerald RC, Hardwick R, Huntsman D, Carneiro F, Guilford P, Blair V, Chung DC, Norton J, Ragunath K, Van Krieken JH, Dwerryhouse S, Caldas C, International Gastric Cancer Linkage Consortium. Hereditary diffuse gastric cancer: updated consensus guidelines for clinical management and directions for future research. J Med Genet 2010;47:436-44.

15 Lowstuter K, Espenschied CR, Sturgeon D, Ricker C, Karam R, LaDuca H, Culver JO, Dolinsky JS, Chao E, Sturgeon J, Speare V, Ma Y, Kingham K, Melas M, Idos GE, McDonnell KJ, Gruber SB. Unexpected CDH1 mutations identified on multigene panels pose clinical management challenges. JCO Precis Oncol 2017;1:1-12.

16 Pesaran T, Karam R, Huether R, Li S, Farber-Katz S, Chamberlin A, Chong H, LaDuca H, Elliott A. Beyond DNA: an integrated and functional approach for classifying germline variants in breast cancer genes. Int J Breast Cancer 2016;2016:1-10.

17 Richards S, Aziz N, Bale S, Bick D, Das S, Gastier-Foster J, Grody WW, Hegde M, Lyon E, Spector E, Voelkerding K, Rehm HL, ACMG Laboratory Quality Assurance Committee. Standards and guidelines for the interpretation of sequence variants: a joint consensus recommendation of the American College of Medical Genetics and Genomics and the Association for Molecular Pathology. Genet Med 2015;17:405-23.

18 Lange K, Papp JC, Sinsheimer JS, Sripracha R, Zhou H, Sobel EM. Mendel: the Swiss army knife of genetic analysis programs. Bioinformatics 2013;29:1568-70.

19. SEER Cancer Statistics Review (CSR) 1975-2014. Stomach. SEER.Cancer.Gov: NCl, 2014. Available: https://seer.cancer.gov/csr/1975_2014/browse_csr.php?sectionSEL= 24\&pageSEL=sect_24_table.07.html

20. SEER Cancer Statistics Review (CSR) 1975-2014. Breast. SEER.Cancer.Gov: NCI 2014. Available: https://seer.cancer.gov/archive/csr/1975_2014/browse_csr.php? sectionSEL=4\&pageSEL=sect_04_table.11.html

21 Wang J, Dang P, Raut CP, Pandalai PK, Maduekwe UN, Rattner DW, Lauwers GY, Yoon SS. Comparison of a lymph node ratio-based staging system with the 7th AJCC system for gastric cancer: analysis of 18,043 patients from the SEER database. Ann Surg 2012;255:478-85.

$22 \mathrm{Li} \mathrm{Cl}$, Uribe DJ, Daling JR. Clinical characteristics of different histologic types of breast cancer. Br J Cancer 2005;93:1046-52.

23 Noone AM, Howlader N, Krapcho M, Miller D, Brest A, Yu M, Ruhl J, Tatalovich Z, Mariotto A, Lewis DR, Chen HS, Feuer EJ, KAe C. SEER Cancer Statistics Review, 1975-2015, 2017. Available: https://seer.cancer.gov/csr/1975_2015/

24 Oliveira C, Bordin MC, Grehan N, Huntsman D, Suriano G, Machado JC, Kiviluoto T, Aaltonen L, Jackson CE, Seruca R, Caldas C. Screening E-cadherin in gastric cancer families reveals germline mutations only in hereditary diffuse gastric cancer kindred. Hum Mutat 2002;19:510-7.

25 Frebourg T, Oliveira C, Hochain P, Karam R, Manouvrier S, Graziadio C, Vekemans M, Hartmann A, Baert-Desurmont S, Alexandre C, Lejeune Dumoulin S, Marroni C, Martin C, Castedo S, Lovett M, Winston J, Machado JC, Attié T, Jabs EW, Cai J, Pellerin P, Triboulet JP, Scotte M, Le Pessot F, Hedouin A, Carneiro F, Blayau M, Seruca R. Cleft lip/palate and $\mathrm{CDH} 1 / \mathrm{E}$-cadherin mutations in families with hereditary diffuse gastric cancer. J Med Genet 2006;43:138-42.

26 Kaurah P, MacMillan A, Boyd N, Senz J, De Luca A, Chun N, Suriano G, Zaor S, Van Manen L, Gilpin C, Nikkel S, Connolly-Wilson M, Weissman S, Rubinstein WS, Sebold C, Greenstein R, Stroop J, Yim D, Panzini B, McKinnon W, Greenblatt M, Wirtzfeld D, Fontaine D, Coit D, Yoon S, Chung D, Lauwers G, Pizzuti A, Vaccaro C, Redal MA, Oliveira C, Tischkowitz M, Olschwang S, Gallinger S, Lynch H, Green J, Ford J, Pharoah $\mathrm{P}$, Fernandez $\mathrm{B}$, Huntsman D. Founder and recurrent $\mathrm{CDH} 1$ mutations in families with hereditary diffuse gastric cancer. JAMA 2007;297:2360-72. 